\section{The oral health status of pre-treatment head and neck cancer patients}

\author{
S. B. Critchlow, ${ }_{1}^{* 1}$ C. Morgan ${ }^{2}$ and T. Leung ${ }^{2}$
}

IN B RIEF
- Reports the first UK data published on
this subject.
- Highlights the poor oral health of head
and neck cancer patients at the time of
diagnosis and the potential impact on
long-term oral health.
- Emphasises the need for comprehensive
preventive regimes in this group of
patients.

\begin{abstract}
Background It is sometimes stated anecdotally that patients with head and neck cancer have poor oral health at the time of oncology diagnosis; however, there is little data in the literature to confirm or refute this claim. Aim To assess, in the first UK study of its type, the oral health status of 100 patients attending for a dental assessment at a single centre before head and neck cancer treatment was commenced. Subjects Sixty-six male patients and 34 female patients were included. Results Of all 100 patients, 2\% (2/100) were edentulous. Of the dentate patients, 71\% (70/98) were clinically diagnosed with periodontal disease. Fifty-one percent (50/98) had a maximum probing pocket depth in excess of $6 \mathrm{~mm}$. The mean number of carious teeth per dentate subject was 2.4 (95\% C.I. 1.6-3.1). Sixty-one percent (60/98) of dentate patients presented with one or more carious teeth. Conclusions Within this cohort, head and neck cancer patients had poor oral health at the time of oncology diagnosis, with caries and periodontal disease being important clinical issues.

The implications for the dental management of these patients are discussed.
\end{abstract}

\section{INTRODUCTION}

The term head and neck cancer (HANC) refers to a wide variety of tumours presenting in the aero-digestive tract of the head and neck region. ${ }^{1}$ Due to the way that cancer statistics are compiled, exact incidence figures for HANC as a whole are difficult to obtain; however, it has been reported that there are approximately 670,000 new cases worldwide annually, amounting to approximately $6 \%$ of all malignant cancers. ${ }^{2}$

Specifically regarding oral cancer, there were 6,236 recorded new cases in the UK in 2009 , amounting to $2 \%$ of all new cancer cases. ${ }^{3}$ Histologically, 95\% of oral cancers are squamous cell carcinomas (SCC). ${ }^{4,5}$ The primary risk factors include smoking, alcohol, chewing of bettle nut/paan, the human papilloma virus, immune status, genetics and socioeconomic factors. ${ }^{6-10}$

The management of HANC in the UK is carried out by multi-disciplinary teams comprising multiple specialists from across the healthcare spectrum. HANC can be treated

Specialist Registrar in Restorative Dentistry, ${ }^{2}$ Consultant in Restorative Dentistry, Department of Restorative Dentistry, Royal London Hospital Dental Institute, New Road, Whitechapel, London, E1 1BB ${ }^{*}$ Correspondence to Simon Bryan Critchlow Email:simon.critchlow@bartshealth.nhs.uk

Online article number E1

Refereed Paper - accepted 25 September 2013

DOI: 10.1038/sj.bdj.2013.1246

${ }^{\circ}$ British Dental Journal 2014; 216: E1 with either radiotherapy alone, surgery alone, or a combination of the two, sometimes with adjuvant chemotherapy. ${ }^{11,12}$ Radiotherapy has a number of side effects relevant to the oral cavity, which are shown in Table 1.

Xerostomia and trismus leave patients who have had radiotherapy at significantly increased risk of dental caries and they can suffer rapid deterioration of their remaining dentition (Fig. 1). ${ }^{13-15}$ This is of particular relevance as many will be prescribed dietary supplements high in refined sugars in order to meet their nutritional requirements around the treatment period.

Guidelines from the National Institute for Health and Care Excellence (NICE) state that all HANC patients should be seen for dental assessment before their oncology treatment. ${ }^{16}$ Due to the complex nature of the decision making and the subsequent oral rehabilitation that is often required for HANC patients, consultants in restorative dentistry are the people best trained and best placed to carry out this assessment. ${ }^{16}$ The role of the restorative consultant can be summarised as follows:

- Optimise oral health before treatment

- Institute prevention

- Plan and facilitate extractions before radiotherapy

- Provide support during treatment

- Provide oral rehabilitation following treatment

- Facilitate maintenance.

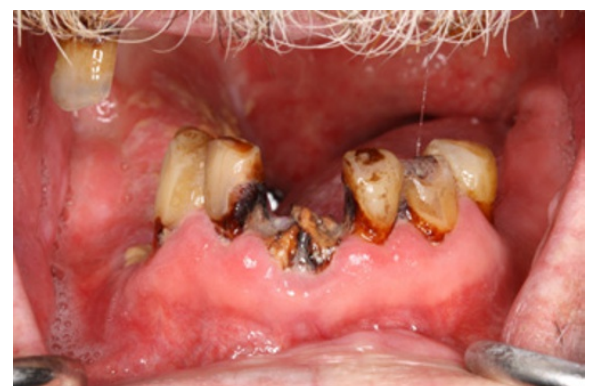

Fig. 1 A classic pattern of radiation caries with frothy, viscous saliva in a patient who underwent radiotherapy

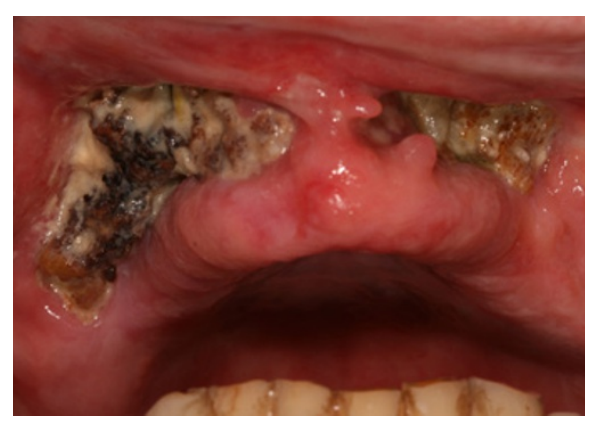

Fig. 2 Osteoradionecrosis of the maxilla following radiotherapy for a squamous cell carcinoma of the nasal septum. Providing oral rehabilitation for this patient was challenging

It is of particular importance that patients are seen for their dental assessment before radiotherapy so a risk assessment can be carried out and teeth of reduced prognosis can be extracted before radiation exposure. Extraction of teeth following radiotherapy 
can be contraindicated due to the risk of developing osteoradionecrosis, which can be severe and debilitating (Fig. 2). ${ }^{17-20}$ The decision to recommend extractions is one that must be made with great care and is influenced by a number of factors. These include oncology factors such as prognosis for curative treatment and the specific planned surgical approach; and the proposed radiotherapy fields, including doses to individual teeth. Patient factors such as oral hygiene and patient expectations; toothwear and existing patterns of tooth loss; as well as individual tooth factors including any existing restorations, caries, periodontal and endodontic status and where each individual tooth sits in an overall strategic plan for oral rehabilitation post-operatively; must also be considered.

Anecdotally, HANC patients have poor dental health at the time of their cancer diagnosis; however, there is no UK data currently available regarding this specific group of patients. In a Brazilian study of 207 pre-radiotherapy patients it was found that $12 \%$ had caries, $41 \%$ periodontal disease and 21\% had one or more retained roots. ${ }^{21}$ Katsura et al. found a mean probing pocket depth of $4.82 \mathrm{~mm}$ in a group of 242 patients before radiotherapy. ${ }^{22}$ Lockhart and Clark found a high incidence of alveolar bone loss (66\%), clinical caries (71\%) and failing restorations (91\%) in 131 pre-radiotherapy patients. ${ }^{23}$

The aim of this study is to present data regarding the levels of dental disease in head and neck cancer patients attending a UK dental hospital for assessment before commencement of their oncology treatment.

\section{MATERIALS AND METHODS}

Records from 100 patients who were referred from the Barts Health HANC multi-disciplinary team (MDT) for preoncology treatment dental assessments at the Royal London Hospital Dental Institute, Whitechapel, London from January 2008 were reviewed. Case notes were examined consecutively by date of dental assessment until a convenience sample of 100 was reached. No power calculation was possible. Inclusion criteria in the study were a diagnosis of HANC at the time of assessment and a complete data set in the case notes. Exclusion criteria were no diagnosis of HANC, previous diagnosis and treatment for HANC and incomplete data in the case notes. Dental assessments took place within two weeks of the patients receiving their oncology diagnosis and all patients were seen for their dental assessment by a consultant in restorative dentistry (CM or TL). The following demographic details were recorded:

- Date of birth

- Sex

- Oncology diagnosis

- Details of planned surgery, radiotherapy or chemotherapy

- Presence of gastro-oesophageal reflux disease (GORD)

- General dental practitioner (GDP) status

- Alcohol consumption

- Smoking status

- Smokeless tobacco use (betel nut/paan).

Patients were categorised as having GORD if they had ticked the relevant box on the medical history questionnaire at their assessment visit. As part of the initial assessment, patients were asked if they visit a dentist regularly or irregularly. Alcohol consumption was self-reported in number of units per week. Smoking status was recorded by asking patients whether they were a current smoker, ex-smoker or non-smoker. The use of smokeless tobacco products or betel nut/paan was also recorded.

As regards clinical data, BPE scores were recorded. In addition, probing pocket depths (PPD) of $4 \mathrm{~mm}$ or more were recorded on individual teeth. On teeth where multiple PPD were measured, the deepest pocket was recorded. A standard dental chart was used to record the DMFT and type of restoration present. Caries was diagnosed using both clinical and radiographic findings. The dental diagnoses made at the time of initial presentation were recorded, as was the treatment plan including the number of planned tooth extractions.

Before oncology treatment, all patients received thorough oral hygiene instruction and diet advice. In addition, all patients were given an information leaflet and a letter to take to their general medical practitioner for the prescription of Duraphat ${ }^{\circledR}$ toothpaste 5,000 ppm fluoride and fluoride mouth rinse for life in accordance with NICE guidelines. ${ }^{16}$ Patients undergoing surgery had their extractions carried out at the same time as their oncology surgery. Those undergoing radiotherapy had their extractions carried out within two weeks of their dental assessment. Socket healing was reviewed before commencement of radiotherapy to ensure soft tissue healing. The minimum time period between completion of extractions and commencement of radiotherapy was two weeks.

Statistical analysis was carried out using SPSS statistical software package (SPSS v. 18.0. SPSS Inc. Chicago Ill).

\begin{tabular}{|c|c|}
\hline Acute & Chronic \\
\hline Dysphagia & Dysphagia \\
\hline Taste disturbances & Taste disturbances \\
\hline Trismus & Trismus \\
\hline \multirow[t]{3}{*}{ Mucositis } & Xerostomia \\
\hline & Neck/cheek fibrosis \\
\hline & Osteoradionecrosis \\
\hline
\end{tabular}

\section{RESULTS}

Sixty-six male patients and 34 female patients were included. Age ranged from 20 years to 88 years with a mean age of 61 (95\% CI 58.2-63.4) years at the time of presentation. Tobacco and alcohol consumption is shown in Tables 2 and 3. Of the 100 patients, 3\% (3/100) of patients reported using betel nut/paan. Self-reported GORD was 9\% (9/100) in this cohort.

Ninety-one percent $(91 / 100)$ of patients presented with a squamous cell carcinoma (SCC). The tumour sites are shown in Figure 3. The TNM staging of the tumours is shown in Figure 4.Ninety percent (90/100) of patients were planned to have radiotherapy as part of their oncology treatment. Sixteen percent $(16 / 100)$ were planned for radiotherapy alone, 27\% (17/100) were planned for chemoradiotherapy, 26\% (26/100) were planned for surgery and radiotherapy and $20 \%(20 / 100)$ were planned for surgery and chemoradiotherapy. Six percent $(6 / 100)$ were planned for surgery alone. In $2 \%$ $(2 / 100)$ of cases it was undecided as to whether radiotherapy would be needed post-operatively. A further 3\% (3/100) were planned for surgery and chemotherapy and one patient was planned for chemotherapy alone.

Forty-three percent $(43 / 100)$ of patients reported visiting a dentist regularly. Two percent (2/100) of patients were edentulous and 64\% (64/100) had 21 or more natural teeth. The mean decayed/ missing/filled teeth (DMFT) score was 19.6 (95\% CI 17.0-21.1).

Regarding the 98 dentate patients, 71\% (70/98) were clinically diagnosed with periodontal disease. Fifty-one percent (50/98) had a maximum probing pocket depth in excess of $6 \mathrm{~mm}$. A further 26\% (25/98) presented with a maximum probing pocket depths of 4-6 $\mathrm{mm}$.

The mean number of carious teeth per dentate patient was 2.4 (95\% CI 1.6-3.1). Sixty-one percent (60/98) of patients presented with one or more carious 
Table 2 Smoking status

\begin{tabular}{l|l|l} 
& Study cohort & Nationally $^{24}$ \\
\hline Smoker & $25 \%$ & $20 \%$ \\
\hline Non-smoker & $43 \%$ & $47 \%$ \\
\hline Ex-smoker & $41 \%$ & $33 \%$
\end{tabular}

\begin{tabular}{|l|l|l|}
\hline Table 3 Alcohol intake & This cohort & Nationally 25 \\
\hline Males $>28$ units per week & $14 \%$ & $27 \%$ \\
\hline Females $>21$ units per week & $4 \%$ & $13 \%$ \\
\hline
\end{tabular}

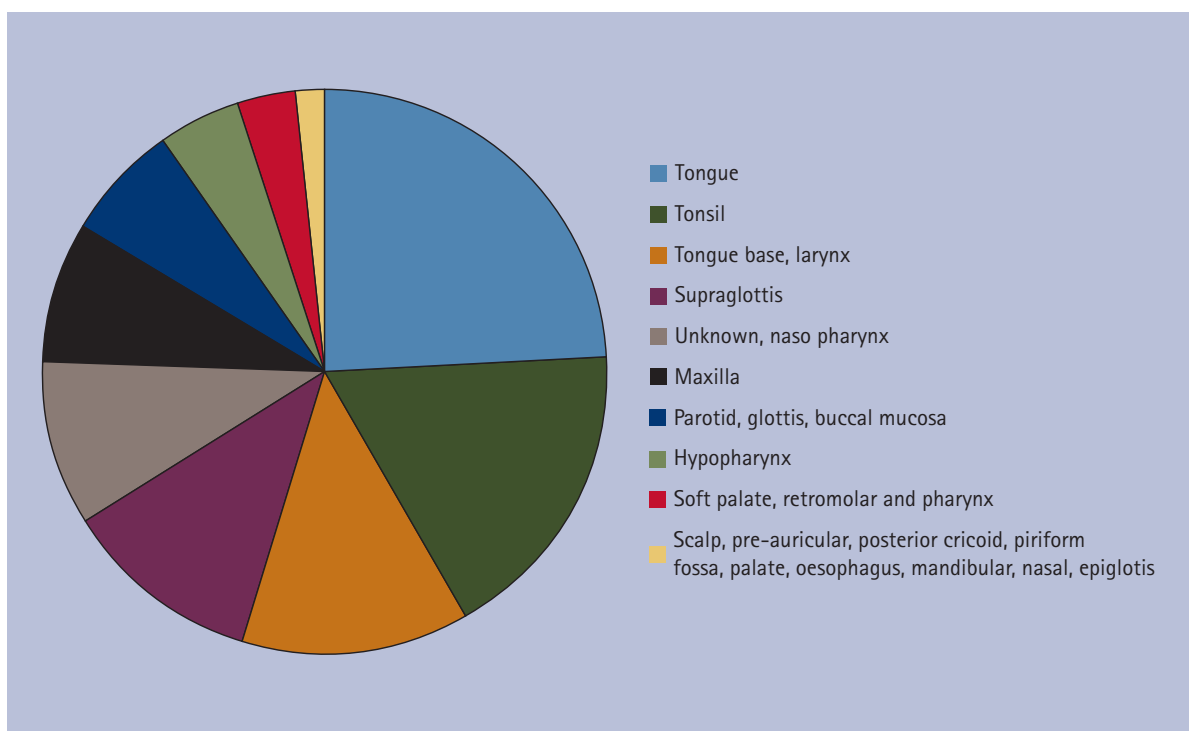

Fig. 3 Tumour sites by frequency

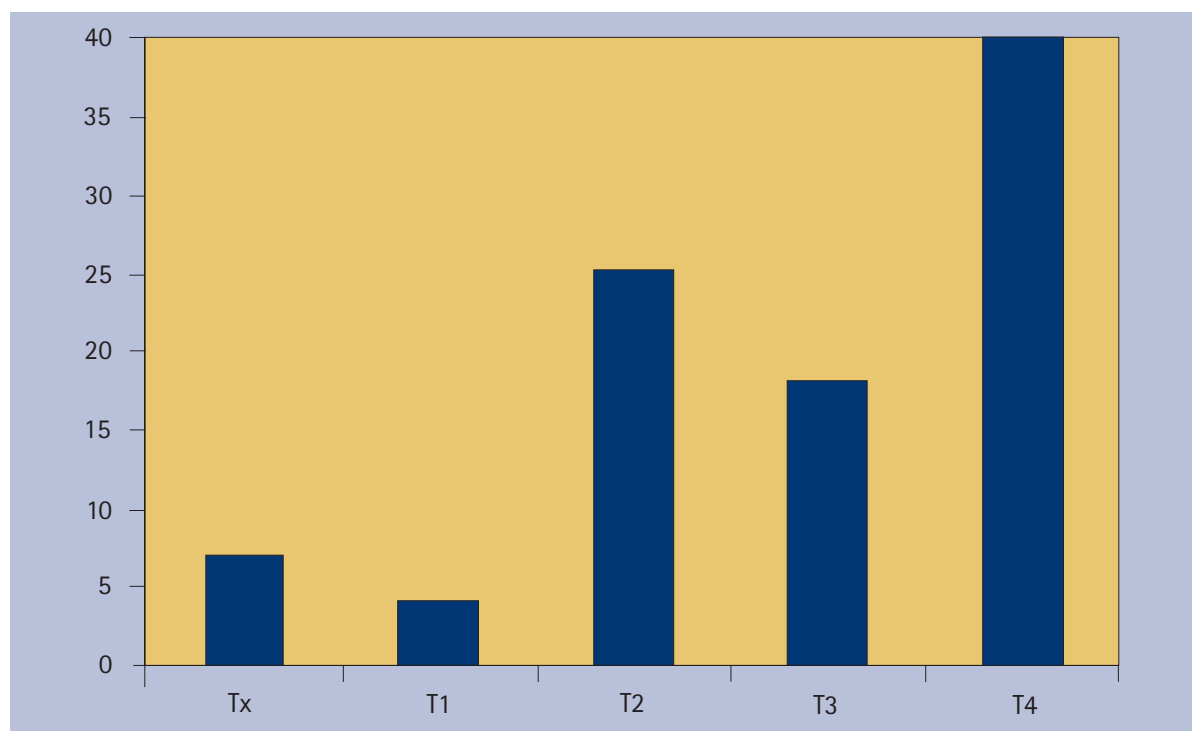

Fig. 4 Tumour staging. Sixty-two patients presented with positive nodal disease and two had distant metastases. The TNM classification was not used in six cases

teeth. The mean number of filled teeth per dentate patient was 4.9 (95\% CI 4.-5.8). 37\% (36/98) of dentate patients had crowned teeth and 12\% (12/98) had fixed bridgework.

The mean number of dental extractions planned per dentate patient was five (95\%
CI 4.2-6.1). In 15\% (15/98) of dentate cases no extractions were planned. Sixty percent (59/98) of dentate patients were planned for five or fewer extractions; the remaining $40 \%$ (39/98) were planned for more than five extractions. Sixty-seven percent (332/494) of teeth planned for extraction were molar teeth, 16\% (78/494) were premolars and 17\% (84/494) were incisors and canines. Which teeth to extract are influenced considerably by radiotherapy being planned as part of the treatment. However, when those patients not undergoing radiotherapy were discounted, the mean number of teeth planned for extraction was unchanged.

\section{DISCUSSION}

This cohort of HANC patients had poor oral health at the time of presentation. Caries and moderate-advanced periodontitis were significant clinical issues. In order to put these findings into context it is important to consider how the patients in this study compare to the general population.

The demographics of this cohort are consistent with national data in terms of sex, age and oncology diagnosis. ${ }^{2,4,5}$ The data on smoking is interesting as it seems that within this cohort of patients there are fewer smokers than in the general population. ${ }^{24}$ It is the experience of the authors that a number of patients will report quitting smoking at the time of their cancer diagnosis, usually a few days before their dental assessment. Therefore, the number of ex-smokers may be overestimated in this group. East London has a large South Asian population for which the chewing of betel nut/paan is culturally important. Three percent of this cohort reported chewing betel nut/ pann, highlighting the importance of routinely asking about smokeless tobacco use (Fig. 5).

Alcohol consumption was also reported to be less in this cohort of patients when compared with national data. ${ }^{25}$ It is unclear why this is the case. Possibilities include patients cutting down on their alcohol intake following cancer diagnosis or difficulties in accurately estimating the number of units consumed per week.

Data from the 2009 Adult Dental Health Survey (ADHS) indicates that $8 \%$ of the adult population have periodontal probing pocket depths in excess of $6 \mathrm{~mm} .{ }^{26} \mathrm{In}$ contrast, $51 \%$ of dentate patients in this cohort had periodontal probing pocket depths in excess of $6 \mathrm{~mm}$. While it is important to recognise the differences between the nature of the adult dental health survey and this study, moderate to advanced periodontal disease is a significant issue for this group of patients. This may be due to a combination of smoking, poor oral hygiene practices and lack of regular attendance at a general dental practitioner. Table 4 shows how the findings from this study compare to 


\section{Table 4 Summary of the relevant literature}

\begin{tabular}{|l|l|l|l|l} 
& $\begin{array}{l}\text { Number of } \\
\text { patients }\end{array}$ & $\begin{array}{l}\text { Percentage of } \\
\text { patients with } \\
\text { carious teeth }\end{array}$ & $\begin{array}{l}\text { Percentage of } \\
\text { patients with } \\
\text { periodontal disease }\end{array}$ & $\begin{array}{l}\text { Mean number } \\
\text { of missing } \\
\text { teeth }\end{array}$ \\
\hline $\begin{array}{l}\text { Lockhart and Clarke } \\
\text { (1994) USA }{ }^{23}\end{array}$ & 131 (75 dentate) & 35 & $\begin{array}{l}66 \text { (flashlight and } \\
\text { tongue spatula) }\end{array}$ & 21.9 \\
\hline $\begin{array}{l}\text { Jham et al. (2008) } \\
\text { Brazil21 }\end{array}$ & 209 (135 dentate) & 12 & $\begin{array}{l}41 \text { (criteria } \\
\text { not clear) }\end{array}$ & Not recorded \\
\hline $\begin{array}{l}\text { MacCarthy et al. } \\
\text { (2007 and 2010) Ireland: } \\
\text { abstracts only } 28,29\end{array}$ & 287 dentate & 68 & $\begin{array}{l}31 \text { (probing pocket } \\
\text { depth }>6 \text { mm) }\end{array}$ & Not recorded \\
\hline $\begin{array}{l}\text { Sennhenn-Kirchner } \\
\text { et al. (2009) German }{ }^{27}\end{array}$ & 36 (25 dentate) & 10 & $\begin{array}{l}47.3(\text { probing pocket } \\
\text { depth }>6 \text { mm) }\end{array}$ & 10.3 \\
\hline $\begin{array}{l}\text { Adult Dental Health } \\
\text { Survey (2009) UK }{ }^{26}\end{array}$ & 6,469 examined & 29 & $\begin{array}{l}8 \text { (probing pocket } \\
\text { depth }>6 \text { mm) }\end{array}$ & 6.3 \\
\hline $\begin{array}{l}\text { Critchlow et al. } \\
\text { (2013) UK }\end{array}$ & 100 (98 dentate) & 61 & $\begin{array}{l}51 \text { (probing pocket } \\
\text { depth }>6 \text { mm) }\end{array}$ & 11.1 \\
\hline
\end{tabular}

other studies in this area along with the ADHS. The periodontal diagnostic criterion used varies significantly between studies, making direct comparisons difficult although a high incidence was reported in several studies. ${ }^{20,22,27,28}$ In addition, the lack of data from other UK centres regarding the oral health status of pre-treatment HANC patients makes it impossible to determine how representative this cohort is of the national picture.

The proportion of patients presenting with one or more carious teeth was $61 \%$ after edentulous patients were discounted. Caries incidence varies widely in the other studies that have been published in this area. ${ }^{20,22,26,27,29}$ This heterogeneity in the data is likely to be due to a variety of factors, not least the fact that these studies come from a wide variety of different countries each with individual dietary factors, habits and oral hygiene practices. Additionally, some studies diagnosed caries clinically, ${ }^{23,26}$ whereas others additionally used radiographs. ${ }^{27}$ In this study, caries was diagnosed using both clinical and radiographic findings.

Ninety percent (90/100) of these patients were planned to undergo radiotherapy as part of their oncology treatment. Given the side effects of radiotherapy, particularly xerostomia, it is of vital importance that these patients are assessed and risk factors addressed both in terms of diet and oral hygiene practices. Caries can progress rapidly and often affects the root surfaces of teeth at and beneath the gingival margin, which can quickly undermine the crown of the tooth (Fig. 1). A high standard of interproximal cleaning with tight recall intervals and careful examination of these areas is required in these cases. This highlights the need for input from specialists in restorative dentistry who are in the position to provide this and also to facilitate the often challenging oral rehabilitation that will be necessary following treatment (Fig. 6). ${ }^{30}$ The need to liaise closely with colleagues, often at very short notice, from oral maxillofacial surgery, ear, nose and throat, oncology, pathology, radiology and general medical and dental practice further re-enforces the vital role played by the restorative dental team.

The mean number of teeth planned for extraction per patient in this cohort was five. Patients can be quite taken aback by the recommendation to remove a significant number of their natural teeth, particularly afford a reasonable prognosis. More molar teeth were planned for extraction than any other tooth type, reflecting the difficulties in maintaining molar teeth following radiotherapy treatment due to trismus and the fact that it is often the molar teeth that lie in the high dose radiotherapy fields, with the posterior mandible being at greatest risk of developing osteoradionecrosis if future extractions are required.17,18,19,20 Excellent communication skills are required to manage this difficult phase of the consultation.

Dental implants can provide patients with a fixed rehabilitation; however, placing implants in irradiated bone risks failure of osseointegration due to a decreased vascular supply, peri-implant infections and possible osteoradionecrosis. ${ }^{31}$ This can, in selected patients, make a strong case for implant placement at the time of oncology surgery (primary placement) although it has been reported that many such implants are either unusable or have a high failure rate. ${ }^{32}$

It is the opinion of the authors that a team approach involving professions complimentary to dentistry is invaluable if they would under normal circumstances

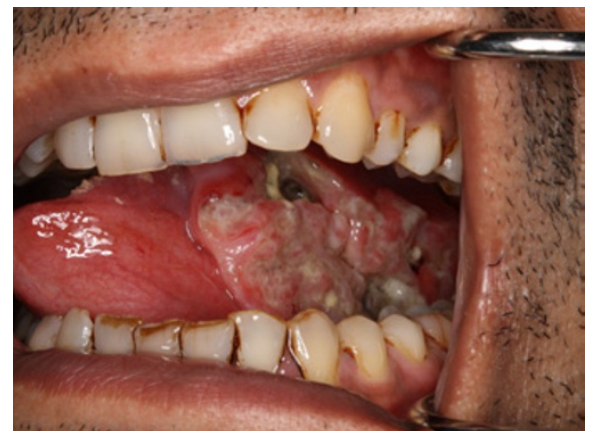

Fig. 5 SCC left lateral border of tongue. This patient chewed betel nut/paan regularly

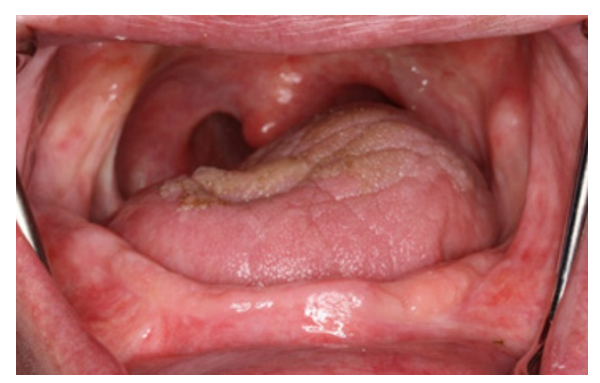

Fig. 6 Severe xerostomia and cheek fibrosis in an edentulous patient who underwent radiotherapy. Providing complete dentures is often difficult due to lack of saliva to provide a peripheral seal and reduced inter-arch space for the dentures

in ensuring that these patients have a chance to maintain their remaining dentitions in a healthy state following their oncology treatment. Hygienists, therapists and oral health educators all play an important part in the management of HANC patients within a consultantlead service. GDPs have an invaluable role as they are often the first healthcare professionals to see new cases of oral cancer and form a key part of the longterm care of HANC patients since wellmaintained and dentally stable patients are often discharged to primary care.

Without intervention from the whole dental team, the consequences of allowing irradiated patient's dentitions to deteriorate can be extreme. As previously stated, extractions are often contraindicated due to the risk of osteoradionecrosis and patients can be condemned to a terminal dentition with no prospect of relief. This has implications for the patient's quality of life as a cancer survivor, not to mention the cost to the health service of trying to maintain teeth of a hopeless prognosis that may have been better extracted following a thorough specialist dental assessment. ${ }^{32}$ It is hoped that the data in this paper can be used to highlight to healthcare commissioners the importance of prevention and ongoing support from the whole restorative team when designing care pathways for head and neck cancer patients. 
1. World Health Organization. International statistical classification of diseases and related health problems. 10th ed. Geneva: WHO, 2010.

2. Parkin D M, Bray F, Ferlay J, Pisani P. Global cancer statistics 2002. CA Cancer J Clin 2005; 55: 74-108.

3. Cancer Research UK. Oral cancer incidence statistics 2010. Online report available at www. cancerresearchuk.org/cancer-info/cancerstats/types/ oral/incidence/ (accessed October 2013).

4. Muir C, Weiland L. Upper aerodigestive tract cancers. Cancer 1995; 75(Suppl 1): 147-153.

5. Ostman J, Anneroth G, Gustafsson H, Tavelin B. Malignant oral tumours in Sweden 1960-1989 - an epidemiological study. Eur J Cancer B Oral Oncol 1995; 31B: 106-112.

6. Conway D I, Petticrew M, Marlborough $\mathrm{H}$, Berthiller J, Hashibe M, Macpherson L M. Socioeconomic inequalities and oral cancer risk: a systematic review and meta-analysis of case-control studies. Int J Cancer 2008; 122: 2811-2819.

7. Kreimer A R, Clifford G M, Boyle P, Franceschi S Human papillomavirus types in head and neck squamous cell carcinomas worldwide: a systematic review. Cancer Epidemiol Biomarkers Prev 2005: 14: $467-475$

8. Llewellyn C D, Johnson N W, Warnakulasuriya K A. Risk factors for squamous cell carcinoma of the ora cavity in young people-a comprehensive literature review. Oral Oncol 2001; 37: 401-418.

9. Thomas S, Wilson A. A quantitative evaluation of the aetiological role of betel quid in oral carcinogenesis. Eur J Cancer B Oral Oncol 1993; 29B: $265-271$.

10. Thomas S J, Harris R, Ness A R et al. Betel quid not containing tobacco and oral leukoplakia: a report on a cross-sectional study in Papua New Guinea and a meta-analysis of current evidence. Int J Cancer 2008; 123: 1871-1876.

11. El-Sayed S, Nelson N. Adjuvant and adjunctive chemotherapy in the management of squamous cell carcinoma of the head and neck region. A metaanalysis of prospective and randomized trials. J Clin Oncol 1996; 14: 838-847.

12. Veldeman L, Madani I, Hulstaert F, De Meerleer G, Mareel M, De Neve W. Evidence behind use of intensity-modulated radiotherapy: a systematic review of comparative clinical studies. Lancet Oncol 2008; 9: 367-375
13. Epstein J B, Robertson M, Emerton S, Phillips N, Stevenson-Moore P. Quality of life and oral function in patients treated with radiation

therapy for head and neck cancer. Head Neck 2001; 23: 389-398.

14. Dreizen S, Daly T E, Drane J B, Brown LR. Oral complications of cancer radiotherapy. Postgrad Med 1977; 61: 85-92.

15. Karmiol M, Walsh R F. Dental caries after radiotherapy of the oral regions. J Am Dent Assoc 1975; $91: 838-845$.

16. The National Institute for Health and Care Excellence. Improving outcomes in head and neck cancers - the manual. London: NICE, 2004. Online report available at www.nice.org.uk/nicemedia/pdf/ csghn_themanual.pdf (accessed October 2013)

17. Reuther T, Schuster T, Mende U, Kübler A. Osteoradionecrosis of the jaws as a side effect of radiotherapy of head and neck tumour patients-a report of a thirty year retrospective review. Int J Oral Maxillofac Surg 2003; 32: 289-295.

18. Assael $L A$. New foundations in understanding osteonecrosis of the jaws. J Oral Maxillofac Surg 2004; 62: 125-126.

19. Notani $\mathrm{K}$ I, Yamazaki Y, Kitada $\mathrm{H}$ et al. Management of mandibular osteoradionecrosis corresponding to the severity of osteoradionecrosis and the method of radiotherapy. Head Neck 2003; 25: 181-186.

20. Thorn J J, Hansen H S, Specht L, Bastholt L. Osteoradionecrosis of the jaws: clinical characteristics and relation to the field of irradiation. J Oral Maxillofac Surg 2000; 58: 1088-1093.

21. Jham B C, Reis P M, Miranda E L et al. Oral health status of 207 head and neck cancer patients before, during and after radiotherapy. Clin Oral Investig 2008; 12: 19-24.

22. Katsura K, Sasai K, Sato K, Saito M, Hoshina H, Hayashi T. Relationship between oral health status and development of osteoradionecrosis of the mandible: A retrospective longitudinal study. Oral Surg Oral Med Oral Pathol Oral Radiol Endod 2008; 105: 731-738.

23. Lockhart P B, Clark J. Pretherapy dental status of patients with malignant conditions of the head and neck. Oral Surg Oral Med Oral Pathol 1994. 77: 236-241.

24. Office for National Statistics. Integrated household survey April 2011 to March 2012: experimental statistics. ONS, 2012. Online report available at www.ons.gov.uk/ons/dcp171778_280451.pdf (accessed October 2013).

25. Alcohol concern information and statistical digest, June 2009. Online factsheet available at www. alcoholconcern.org.uk/assets/files/Publications/ Drinking\%20Patterns\%20Factsheet.pdf (accessed October 2013).

26. Health and Social Care Information Centre. Adult dental health survey 2009. HSCIC, 2011. Online report available at http://www.hscic.gov.uk/pubs/ dentalsurveyfullreport09 (accessed October 2013).

27. Sennhenn-Kirchner S, Freund F, Grundmann S et al. Dental therapy before and after radiotherapyan evaluation on patients with head and neck malignancies. Clin Oral Investig 2009; 13: 157-164.

28. MacCarthy D. Baseline periodontal status, oralhygiene and smoking-habits in H\&N cancer patients. Poster. The Preliminary Program for IADR General Session (July 14-17, 2010). Online abstract available at http://iadr.confex.com/iadr/2010barce/ preliminaryprogram/abstract_139283.htm (accessed October 2013).

29. MacCarthy D, Omer O, Kearney J. Profile of head and neck radiation therapy patients seen in the Dublin Dental School \& Hospital (DDSEHH) from 1997-2006. Oral and poster presentations. The Preliminary Program for Irish Division IADR Annual Scientific Meeting (October 4-5, 2007). Online abstract available at https://iadr.confex.com/iadr/irish07/ preliminaryprogram/abstract_102125.htm (accessed October 2013).

30. Ray-Chaudhuri A, Shah K, Porter R J. The oral management of patients who have received radiotherapy to the head and neck region. Br Dent J 2013; 214: 387-393.

31. Inde S, Kopp S, Gundlach K, Konstantinović V S Effects of radiation therapy on craniofacial and dental implants: a review of the literature. Oral Surg Oral Med Oral Pathol Oral Radiol Endod 2009; 107: 56-65.

31. Fenlon M R, Lyons A, Farrell S, Bavish K, Banerjee A, Palmer R. Factors affecting survival and usefulness of implants in vascularised free composite grafts used in post-head and neck cancer reconstruction lin Implant Dent Relat Res 2012; 14: 266-272.

32. Rogers S N. Quality of life perspectives in patients with oral cancer. Oral Oncol 2010; 46: 445-447. 